\title{
SISTEMA RADICULAR DE QUATRO PORTA-ENXERTOS SOB COPA DE TANGERINA 'PONCÃ'
}

\author{
Root system of four rootstocks for 'Ponkan' mandarin trees
}

\author{
Carmen Silvia Vieira Janeiro Neves ${ }^{1}$, Neusa Maria Colauto Stenzel ${ }^{2}$, Sergio Luiz Colucci de Carvalho ${ }^{2}$, \\ Thiago Luiz Ragugnetti Furlaneto ${ }^{3}$, Sérgio Hideki Okumoto ${ }^{3}$
}

\begin{abstract}
RESUMO
Estudos realizados a campo sobre a extensão e a distribuição das raízes são importantes para a tomada de decisões referentes ao manejo das culturas. Objetivou-se com este trabalho estudar o sistema radicular dos porta-enxertos limão 'Cravo' (Citrus limonia Osb.), limão ‘Rugoso' (Citrus jambhiri Lush.), tangerina 'Cleópatra' (Citrus reticulata Blanco) e citrange C 13 [Citrus sinensis (L.) Osb. x Poncirus trifoliata (L.) Raf.], sob copa de tangerina 'Poncã' (Citrus reticulata Blanco), com o método da trincheira. O delineamento experimental foi em blocos ao acaso, com quatro tratamentos e três repetições, com uma trincheira por parcela. A tangerina Cleópatra apresentou maior quantidade de raízes somente na linha de plantio quando comparada com os outros portaenxertos. A profundidade efetiva do sistema radicular foi de 0,36 a $0,75 \mathrm{~m}$ na linha de plantio e de 0,46 a $0,74 \mathrm{~m}$ na entrelinha. Não houve diferenças significativas para os porta-enxertos em relação à distância efetiva do sistema radicular.
\end{abstract}

Termos para indexação: Citrus, raízes, método da trincheira.

\begin{abstract}
Studies accomplished in the field about the extension and distribution of roots are important for management practices. The aim of this work was to study the root system of four rootstocks such as Rangpur lime (Citrus limonia Osb.), Rough lemon (Citrus jambhiri Lush.), Cleopatra mandarin (Citrus reticulate Blanco) and C 13 citrange [Citrus sinensis (L.) Osb. x Poncirus trifoliata (L.) Raf.], budded under 'Ponkan' mandarin trees (Citrus reticulata Blanco), using the trench method. The experimental outline was the one of randomized blocks with four treatments and three replications, with one trench for each plot. The Cleopatra mandarin presented higher amount of roots only in the row when compared to other rootstocks. The effective root depth ranged from 0.36 to $0.75 \mathrm{~m}$ in the rows and from $0.46 \mathrm{~m}$ to 0.74 in inter rows. There were no significant differences among rootstocks concerning radicular effective root distance.
\end{abstract}

Index terms: Citrus, roots, trench profile method.

(Recebido em 21 de dezembro de 2005 e aprovado em 25 de junho de 2007)

\section{INTRODUÇÃO}

A tangerina 'Poncã' (Citrus reticulata Blanco) é uma cultivar de colheita precoce, vigorosa, com hábito de crescimento vertical, com tendência a alternância de produção; frutos com poucas sementes, suculenta, de sabor agradável, com casca fofa e alaranjada (HODGSON, 1967). No Brasil, esta tangerina é a mais importante, plantada principalmente nas regiões Sudeste e Sul, onde mostra adaptação excelente para as condições edafoclimáticas (FIGUEIREDO, 1991) e o limão ‘Cravo’ é o principal porta-enxerto utilizado. Embora este porta-enxerto induza características satisfatórias para a tangerineira 'Poncã' e tenha tolerância alta ao vírus da tristeza, ele tem resistência moderada a Phytophthora citrophthora e
Phytophthora parasitica e é suscetível ao declínio dos citros, sendo importante a busca de opções para a diversificação de porta-enxertos (POMPEU JÚNIOR, 1991).

$\mathrm{Na}$ maioria dos estudos que envolvem a experimentação com porta-enxertos potenciais para o uso na citricultura, o foco principal tem sido a produtividade $\mathrm{e}$ a qualidade dos frutos. No entanto, estudos sobre o sistema radicular das plantas são de grande importância por seu papel na sustentação e na absorção de água e nutrientes. As informações sobre a distribuição e a extensão do sistema radicular dos diferentes porta-enxertos são fundamentais para tomada de decisões sobre tratos culturais, como espaçamento de plantio, manejo do solo, adubação e irrigação localizada. Os principais fatores que têm sido identificados como determinantes da distribuição

${ }^{1}$ Engenheira Agrônoma, Professora - Departamento de Agronomia - Centro de Ciências Agrárias - Universidade Estadual de Londrina/UEL - Cx.P. 6001 86051-990 - Londrina, PR - csvjneve@uel.br - Bolsista CNPq

${ }^{2}$ Engenheiros Agrônomos, Doutores, Pesquisadores - Instituto Agronômico do Paraná/lAPAR - Cx. P. 481 - 86001-970 - Londrina, PR - nstenzel@pr.gov.br; slcarva@iapar.br

${ }^{3}$ Engenheiros Agrônomos - Departamento de Agronomia - Centro de Ciências Agrárias - Universidade Estadual de Londrina/UEL - Cx.P. 6001 - $86051-990$ Londrina, PR - furlaneto_agro@hotmail.com; okumoto@bol.com.br - Bolsista PIBIC / CNPq 
e da quantidade das raízes das plantas cítricas são características químicas e físicas do solo (AVILAN et al., 1986), tipo de muda (DAVOGLIO JÚNIOR et al., 2006), tratos culturais e manejo do solo (NEVES et al., 1998), potencial genético, tanto da copa quanto do porta-enxerto (MONTENEGRO, 1960), a idade da planta e suas condições fitossanitárias (CASTLE, 1980). O crescimento das raízes de plantas cítricas pode atingir de 1,2 a 1,5 $\mathrm{m}$ de profundidade; porém, a maior concentração situa-se até $0,6-0,9 \mathrm{~m}$ (MONTENEGRO, 1960).

Os porta-enxertos limão 'Cravo', limão 'Rugoso', tangerina 'Cleópatra' e citrange C 13 têm se destacado com boa produtividade para a tangerineira 'Poncã' nas condições do Norte do Paraná (STENZEL et al., 2003). Assim, objetivouse com este presente trabalho estudar a distribuição e a quantidade de raízes desses quatro porta-enxertos nessa região, com vistas a direcionar o manejo da cultura.

\section{MATERIAL E MÉTODOS}

O experimento foi conduzido em pomar instalado no município de Maringá, Norte do Paraná, na latitude de $23^{\circ} 22^{\prime} \mathrm{S}$ e longitude $52^{\circ} 4^{\prime} \mathrm{W}$. O solo da região está classificado como Latossolo Vermelho distroférrico (EMBRAPA, 1999) e o clima, de acordo com a classificação de Köppen, é do tipo Cfa, subtropical úmido. A temperatura média anual é de $21^{\circ} \mathrm{C}$ e a precipitação é de $1500 \mathrm{~mm}$ anuais.

A copa utilizada foi a tangerina 'Poncã' (Citrus reticulata Blanco) e os porta-enxertos foram os seguintes: limão ‘Cravo' (Citrus limonia Osb.); limão ‘Rugoso' (Citrus jambhiri Lush.); tangerina 'Cleópatra' (Citrus reticulata Blanco) e citrange C13 [Citrus sinensis (L.) Osb. x Poncirus trifoliata (L.) Raf.]. O pomar foi implantado com mudas de torrão, em dezembro de 1988, em solo preparado e corrigido em área total (calcário dolomítico 5 ton $\mathrm{ha}^{-1}$, parcelado em duas vezes), sendo o plantio realizado em sulcos, no espaçamento de 7 x $4 \mathrm{~m}$. Para o controle de plantas daninhas, até o terceiro ano após a implantação do pomar, foram realizadas capinas manuais. A partir desse período, usou-se roçadora nas entrelinhas de plantio e herbicida residual na linha. Foram realizadas calagem $\left(5130 \mathrm{~kg} \mathrm{ha}^{-1} \mathrm{em} 1998\right.$ e 2977 $\mathrm{kg} \mathrm{ha}^{-1}$ de calcário dolomítico em 1999, com aplicação superficial na faixa da adubação) e adubação mineral de acordo com as recomendações de Vitti (1990). Os tratos fitossanitários foram realizados sempre que necessário e o pomar foi conduzido sem irrigação.

A avaliação das raízes foi realizada pelo método da trincheira (BÖHM, 1979) no primeiro semestre de 2001, quando as plantas estavam com 12 anos de idade. $\mathrm{O}$ delineamento experimental foi em blocos ao acaso, com quatro tratamentos e três repetições, com uma trincheira por parcela. As trincheiras foram abertas perpendicularmente à linha de plantio, com comprimento de 3,5 m desde a linha de plantio até o meio da rua, com profundidade de $1,0 \mathrm{~m}$ e a 0,10 $\mathrm{m}$ de distância do tronco. As observações foram realizadas também paralelamente à linha de plantio nas mesmas trincheiras, com largura de 2,0 m, profundidade de $1,0 \mathrm{~m}$ e a $0,10 \mathrm{~cm}$ do tronco.

As raízes foram expostas com o auxílio de um rolo escarificador e pintadas com tinta branca. Para a tomada das imagens foi colocada uma moldura de madeira com fios de nylon, formando quadros de $0,25 \times 0,25 \mathrm{~m}$ (CINTRA \& NEVES, 1996). De cada quadro foi tomada uma imagem com câmera fotográfica digital. As imagens obtidas foram quantificadas através do programa SIARCS/EMBRAPA (CRESTANA et al., 1994; JORGE et al., 1996), com resultados de comprimento das raízes presentes em cada quadro.

Os seguintes dados foram calculados: comprimento das raízes, por trincheira, na linha, na entrelinha e total; comprimento de raízes por profundidade, na linha e na entrelinha de plantio; e distância e profundidade efetivas que representam o limite até onde se encontram $80 \%$ das raízes (KLAR, 1991). Realizou-se análise de variância e as médias foram comparadas pelo teste de Duncan a 5\% de significância.

\section{RESULTADOS E DISCUSSÃO}

A tangerina ‘Cleópatra' apresentou maior quantidade de raízes na linha de plantio (Tabela 1), enquanto que na entrelinha e no total não se detectou diferença significativa entre os porta-enxertos estudados. A tangerina 'Cleópatra' é considerada um porta-enxerto que proporciona grande crescimento à planta (POMPEU JÚNIOR, 1991), o que pode explicar seu maior desenvolvimento radicular. Corroborando com esta afirmação, Stenzel et al. (2003), que avaliaram o tamanho das plantas neste mesmo experimento, verificaram que a tangerina 'Cleópatra' e o limão 'Rugoso' induziram maior altura e volume de copa à planta. Da mesma forma, Cintra et al. (1999) observaram que a tangerina 'Cleópatra' teve a maior quantidades de raízes sob copa de laranja 'Pêra' em solos de tabuleiros costeiros do Nordeste brasileiro.

Em relação à quantidade de raízes por profundidade, todos os porta-enxertos estudados apresentaram mais raízes na camada mais superficial $(0,0-0,25 \mathrm{~m})$, tanto na linha de plantio quanto na entrelinha (Figuras 1 e 2). Essa quantidade de raízes decresceu na camada seguinte $(0,25-$ $0,50 \mathrm{~m}$ ) em cerca de $50 \%$ na linha de plantio e cerca de $35 \%$ de redução na entrelinha, com exceção da tangerina 'Cleópatra' na entrelinha, que teve redução de apenas aproximadamente $10 \%$, demonstrando o maior aprofundamento das raízes desse porta-enxerto, fato também salientado por Cintra et al. (1999). 
Tabela 1 - Total de comprimento de raízes $(\mathrm{cm})$ por trincheira na linha, na entrelinha e total (linha + entrelinha) de portaenxertos sob tangerina 'Poncã'. Maringá - PR, 2001.

\begin{tabular}{lccc}
\hline \multicolumn{1}{c}{ Porta-enxerto } & Linha & Entrelinha & Total (Linha+Entrelinha) \\
\cline { 2 - 4 } & & Comprimento de raízes (cm) & \\
\cline { 2 - 4 } Limão Cravo & $599,8 \mathrm{~b}$ & $1.538,1 \mathrm{a}$ & $2.137,9 \mathrm{a}$ \\
Limão Rugoso & $570,1 \mathrm{~b}$ & $1.546,8 \mathrm{a}$ & $2.116,9 \mathrm{a}$ \\
Tang. Cleópatra & $1.655,8 \mathrm{a}$ & $2.227,6 \mathrm{a}$ & $3.883,5 \mathrm{a}$ \\
Citrange C13 & $449,3 \mathrm{~b}$ & $1.882,3 \mathrm{a}$ & $2.331,6 \mathrm{a}$ \\
\hline C.V. $(\%)$ & 50,17 & 36,33 & 37,24 \\
\hline
\end{tabular}

*Médias seguidas da mesma letra na coluna, não diferem estatisticamente entre si, no nível de 5\% de probabilidade pelo teste de Duncan.

Comprimento de raízes na entrelinha $(\mathrm{cm})$

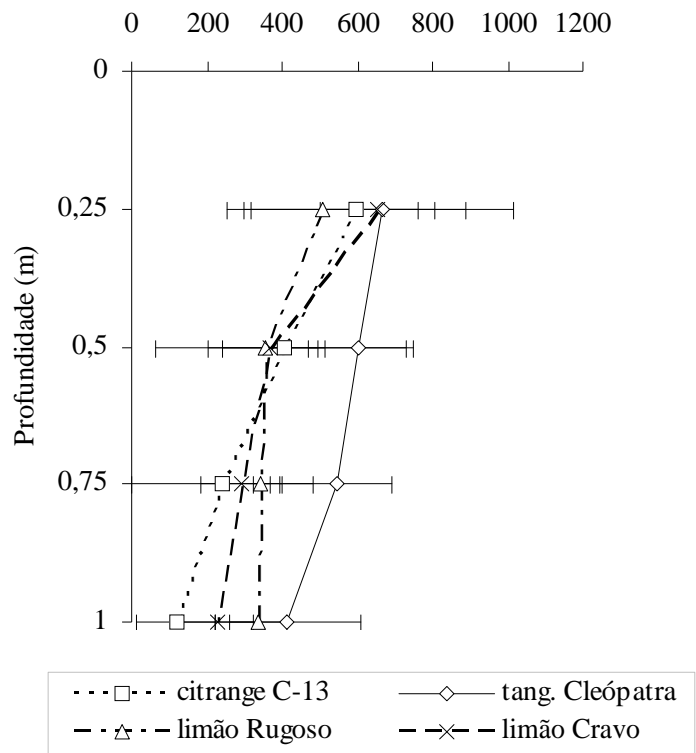

Figura 1-Comprimento de raízes por profundidade de portaenxertos sob tangerina 'Poncã' em quatro profundidades na linha de plantio (média de três repetições). Maringá PR, 2001.

Para a distribuição de raízes por distância do tronco na linha de plantio (Figura 3) houve uma distribuição uniforme desde a distância de $0,50 \mathrm{~m}$ a partir do tronco até $2,00 \mathrm{~m}$ que representa a metade do espaçamento entre as plantas, exceto para tangerina Cleópatra, que teve um aumento na quantidade de raízes na distância de 0,75 a 1,25m. Na entrelinha, todos os portaenxertos estudados tiveram maior distribuição a partir de 1,0 m de distância do tronco até cerca de 2,5 m e a partir daí apresentando comportamento uniforme até a distância

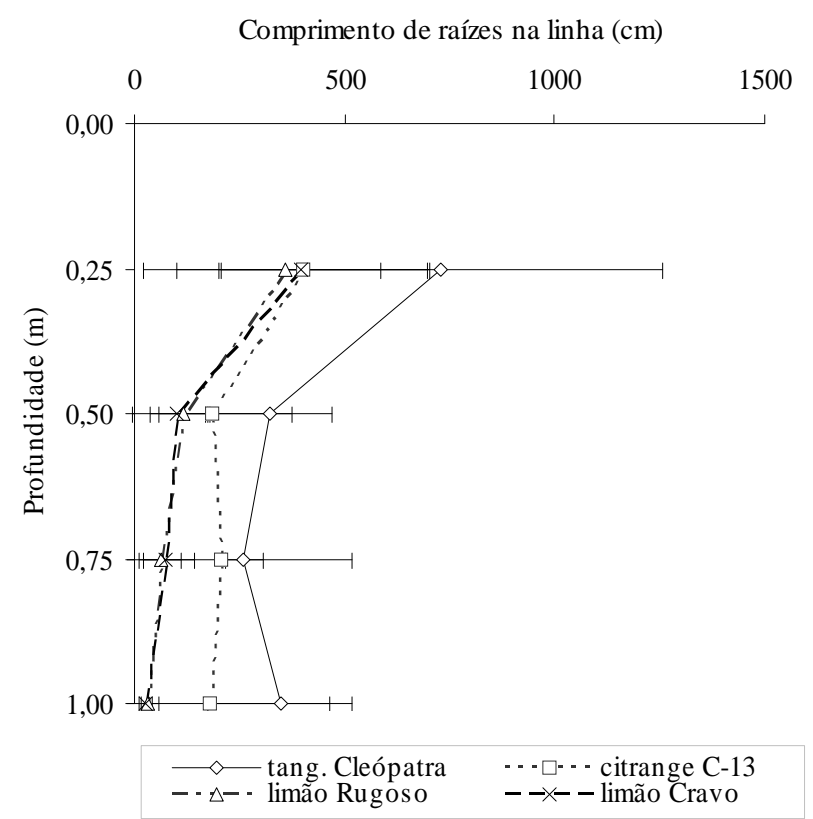

Figura 2 - Comprimento de raízes por profundidade de porta-enxertos de tangerina 'Poncã' em quatro profundidades na entrelinha de plantio (média de três repetições). Maringá - PR, 2001.

de 3,5 m que representa a metade do espaçamento na entrelinha (Figura 4).

Em relação às distâncias efetivas (Tabela 2), não foram observadas diferenças estatísticas entre os portaenxertos, obtendo-se valores de 1,60 a 1,98 m na linha e de 2,29 a 2,61 m na entrelinha. Oliveira et al. (1998) determinaram a distância efetiva de 1,50 m para tangerina 'Cleópatra' sob copa de laranjeira 'Pera' em solo franco-argiloso. Neves et al. (2004), para copa de lima ácida 'Tahiti', em espaçamento de 8 x $6 \mathrm{~m}$ no mesmo local do presente trabalho obtiveram 


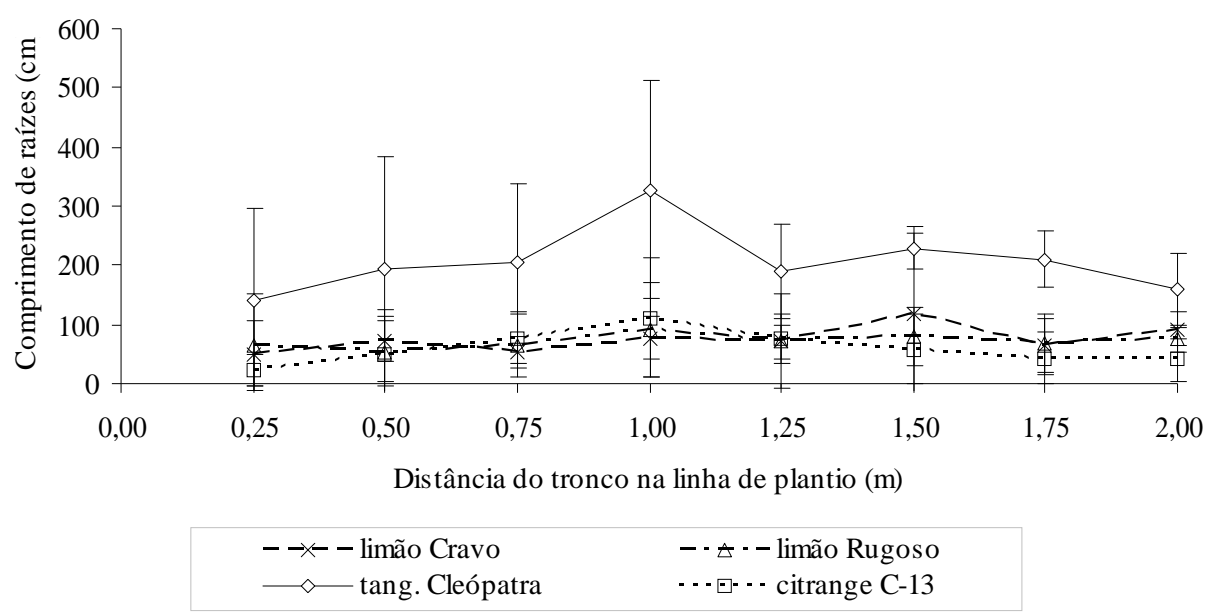

Figura 3 - Comprimento de raízes por perfil avaliado de porta-enxertos de tangerina 'Poncã' em relação à distância do tronco na linha de plantio (média de três repetições). Maringá - PR, 2001.

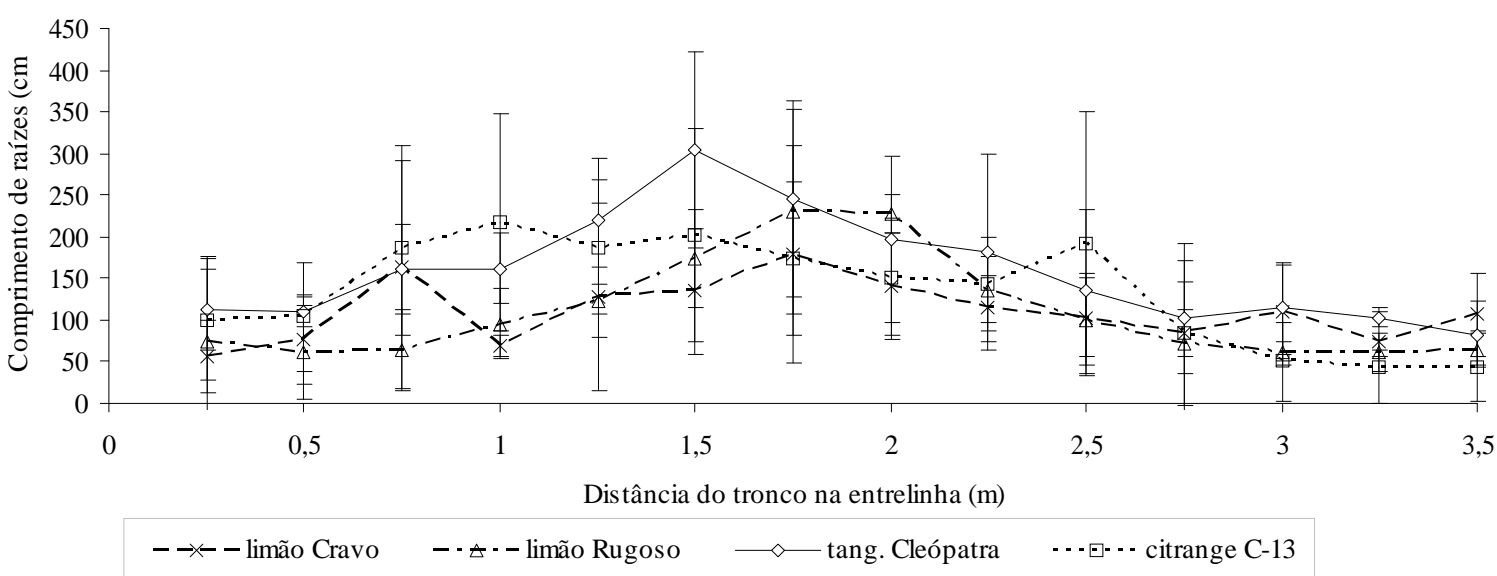

Figura 4 - Comprimento de raízes por perfil avaliado de porta-enxertos de tangerina 'Poncã' em relação à distância do tronco na entrelinha de plantio (média de três repetições). Maringá - PR, 2001.

Tabela 2 - Distâncias e profundidades efetivas do sistema radicular de porta-enxertos de tangerina 'Poncã' na linha e entrelinha de plantio (média de três repetições). Maringá - PR, 2001.

\begin{tabular}{lccccc}
\hline & Raio da copa & \multicolumn{2}{c}{ Distância efetiva $(\mathrm{m})$} & \multicolumn{2}{c}{ Profundidade efetiva $(\mathrm{m})$} \\
\cline { 2 - 6 } \multicolumn{1}{c}{ Porta-enxerto } & $(\mathrm{m})$ & Linha & Entrelinha & Linha & Entrelinha \\
\hline Limão Cravo & $2,20 \mathrm{bc}$ & $1,69 \mathrm{a}$ & $2,61 \mathrm{a}$ & $0,36 \mathrm{a}$ & $0,60 \mathrm{ab}$ \\
Limão Rugoso & $2,35 \mathrm{ab}$ & $1,71 \mathrm{a}$ & $2,31 \mathrm{a}$ & $0,41 \mathrm{a}$ & $0,74 \mathrm{a}$ \\
Tang. Cleópatra & $2,50 \mathrm{a}$ & $1,60 \mathrm{a}$ & $2,36 \mathrm{a}$ & $0,75 \mathrm{a}$ & $0,73 \mathrm{a}$ \\
Citrange C13 & $2,20 \mathrm{bc}$ & $1,98 \mathrm{a}$ & $2,29 \mathrm{a}$ & $0,52 \mathrm{a}$ & $0,46 \mathrm{~b}$ \\
\hline CV $(\%)$ & - & 18,7 & 15,3 & 43,1 & 14,7 \\
\hline
\end{tabular}

*Médias seguidas da mesma letra na coluna, não diferem estatisticamente entre si, no nível de $5 \%$ de probabilidade pelo teste de Duncan. 
distância efetiva na linha e entrelinha, respectivamente, de 2,30 e 3,12 m para limão 'Cravo' e 2,35 e 3,25 para citrange $\mathrm{C} 13$, indicando que o espaçamento e a copa utilizada também influenciam o desenvolvimento das raízes.

Observou-se que a distância efetiva da entrelinha atingiu valores muito próximos aos do raio da copa (Tabela 2), indicando uma maior concentração de raízes sob a copa, o mesmo observado por Machado \& Coelho (2000) em limão ‘Cravo' sob lima ácida 'Tahiti’ e Neves et al. (2004) em diversos porta-enxertos, também sob lima ácida 'Tahiti'. Estes resultados estão de acordo com a recomendação do Grupo Paulista de Adubação e Calagem para Citros (1994), que indicam adubação em faixa de largura igual ao raio da copa, sendo $2 / 3$ dentro da projeção da copa e $1 / 3$ fora, para plantas cítricas a partir de três anos de idade.

Para as profundidades efetivas (Tabela 2), na linha observou-se que a profundidade até onde se encontram $80 \%$ das raízes foi $0,75 \mathrm{~m}$ para tangerina 'Cleópatra', porém sem diferir dos demais porta-enxertos que tiveram de 0,36 a $0,52 \mathrm{~m}$, sendo estes últimos valores próximos dos observados por Neves et al. (2004). Para a entrelinha, a tangerina 'Cleópatra' e o limão 'Rugoso' tiveram 0,73 e 0,74 que foi significativamente maior do que o obtido pelo citrange $\mathrm{C} 13(0,46 \mathrm{~m})$, mas sem diferir da profundidade de 0,60 m obtida pelo limão ‘Cravo'. O maior aprofundamento observado em tangerina 'Cleópatra' e limão 'Rugoso' pode ser decisivo para a produção de frutos quando ocorrer estresse hídrico, pois, nessas condições, essa característica permite a exploração de maior volume do solo, justamente nas camadas onde ainda existe água (MAZZA et al., 1994).

\section{CONCLUSÕES}

Nas condições do presente trabalho, para o manejo do solo na cultura deve-se levar em consideração que a tangerina 'Cleópatra' apresenta maior quantidade de raízes na linha de plantio, mas na entrelinha e no total de raízes (linha mais entrelinha) não há diferenças entre os portaenxertos.

A profundidade efetiva do sistema radicular é de 0,36 a $0,75 \mathrm{~m}$ na linha de plantio e de 0,46 a $0,74 \mathrm{~m}$ na entrelinha, destacando-se a tangerina ‘Cleópatra' e o limão 'Rugoso' com maior profundidade efetiva na entrelinha.

\section{REFERÊNCIAS BIBLIOGRÁFICAS}

AVILAN, L.; LEAL, F.; MENESES, L.; SUCRE, R.; GARCIA, M. L. Distribución del sistema radical de las cítricas en algunos suelos de Venezuela. Fruits, Paris, v. 41, n. 11, p. 655-668, 1986.
BÖHM, W. Methods of studying root systems. Berlin: Springer-Verlag, 1979. 188 p.

CASTLE, W. S. Fibrous root distribution of 'Pineapple' Orange trees on Rough Lemon rootstock at three spacings. Journal of the American Society for Horticultural Science, Alexandria, v. 105, n. 3, p. 478-480, 1980.

CINTRA, F. L. D.; LIBARDI, P. L.; JORGE, L. A. C. Distribuição do sistema radicular de porta-enxertos de citros em ecossistemas de tabuleiro costeiro. Revista Brasileira de Fruticultura, Jaboticabal, v. 21, n. 3, p. 313317, 1999.

CINTRA, F. L. D.; NEVES, C. S. V. J. Aspectos metodológicos do estudo do sistema radicular de plantas perenes através de imagens. Boletim Informativo da Sociedade Brasileira de Ciência do Solo, Campinas, v. 21, n. 3, p. 91-94, 1996.

CRESTANA, S.; GUIMARÃES, M. F.; JORGE, L. A. C.; RALISCH, R.; TOZZI, C. L.; TORRE, A.; VAZ, C. M. P. Avaliação da distribuição de raízes no solo auxiliada por processamento de imagens digitais. Revista Brasileira de Ciência do Solo, Campinas, v. 18, p. 365-371, 1994.

DAVOGLIO JÚNIOR, A. C.; BORDIN, I.; NEVES, C. S. V. J. Sistema radicular e desenvolvimento de plantas cítricas provenientes de viveiro telado e aberto. Revista Brasileira de Fruticultura, Jaboticabal, v. 28, p. 172-175, 2006.

EMPRESA BRASILEIRA DE PESQUISA AGROPECUÁRIA. Solos: sistema brasileiro de classificação de solos. Rio de Janeiro, 1999. 412 p.

FIGUEIREDO, J. O. Variedades copa de valor comercial. In: RODRIGUEZ, O.; VIEGAS, F. C. P.; POMPEU JÚNIOR, J.; AMARO, A. A. (Eds.). Citricultura brasileira. 2. ed. Campinas: Fundação Cargill, 1991. v. 1, p. 228-264.

GRUPO PAULISTA DE ADUBAÇÃO E CALAGEM PARA CITROS. Recomendações de adubação e calagem para citros no estado de São Paulo. 3. ed. Cordeirópolis, 1994. Edição especial.

HODGSON, R. W. Horticultural varieties of Citrus. In: REUTHER, W.; WEBBER, H. J.; BATCHELOR, L. D. The citrus industry. Riverside: University of California, 1967. v. 1, cap. 4, p. 431-591. 
JORGE, L. A. C.; RALISCH, R.; ABI SAAB, O. J. G.; MEDINA, C. C.; GUIMARÃES, M. F.; NEVES, C. S. V. J.; CRESTANA, S.; CINTRA, F. L. D.; BASSOI, L. H.; FERNANDES, S. B. V. Recomendações práticas para aquisição de imagens digitais analisadas através do SIARCS. São Carlos: Embrapa; CNPDIA, 1996. (Circular técnica, 1).

KLAR, A. E. Irrigação: freqüência e quantidade de aplicação. São Paulo: Nobel, 1991. 156 p.

MACHADO, C. C.; COELHO, R. D. Estudo da distribuição espacial do sistema radicular do limão 'Cravo' enxertado com lima ácida 'Tahiti'. Laranja, Cordeirópolis, v. 21, p. 359-380, 2000.

MAZZA, J. A.; VITTI, G. C.; PEREIRA, H. S.; MENEZES, G. M.; TAGLIARINI, C. H. Influência da compactação no desenvolvimento do sistema radicular de citros: sugestão de método qualitativo de avaliação e recomendação de manejos. Laranja, Cordeirópolis, v. 15, n. 2, p. 251-262, 1994.

MONTENEGRO, H. W. S. Contribuição ao estudo do sistema radicular das plantas cítricas. 1960. $143 \mathrm{f}$. Tese (Doutorado) - Escola Superior de Agricultura "Luiz de Queiroz”, Universidade de São Paulo, Piracicaba, 1960.

NEVES, C. S. V. J.; DECHEN, A. R.; FELLER, C.; ABI SAAB, O. J. G.; PIEDADE, S. M. S. Efeito do manejo do solo no sistema radicular de tangerineira "Poncã" enxertada sobre limoeiro 'Cravo` em latossolo roxo. Revista Brasileira de Fruticultura, Cruz das Almas, v. 20, n. 2, p. 146-253, 1998.

NEVES, C. S. V. J.; MURATA, I. M.; STENZEL, N. M. C.; MEDINA, C. C.; BORGES, A. V.; OKUMOTO, S. H.; LEE, R. H. C.; KANAI, H. T. Root distribution of rootstocks for 'Tahiti' lime. Scientia Agricola, Piracicaba, v. 61, n. 1, p. 9499, 2004.

OLIVEIRA, L. F. C.; VIEIRA, D. B.; SOUZA, I. S. Estudo do sistema radicular de tangerineira Cleópatra com copa de laranja Pêra. Laranja, Cordeirópolis, v. 19, n. 1, p. 117-131, 1998.

POMPEU JÚNIOR, J. Porta-enxertos. In: RODRIGUEZ, O; VIÉGAS, F. C. P.; POMPEU JÚNIOR, J.; AMARO, A. A. (Eds.). Citricultura brasileira. 2. ed. Campinas: Fundação Cargill, 1991. p. 265-280.

STENZEL, N. M. C.; NEVES, C. S. V. J.; GOMES, J. C.; MEDINA, C. C. Performance of 'Ponkan' mandarin on seven rootstocks. Hortscience, Alexandria, v. 38, n. 2, p. 176-178, 2003.

VITTI, G. C. Nutrição e adubação de pomares. In: ENCONTRO PARANAENSE DE CITRICULTURA, 2., 1989, Maringá. Anais... Maringá: Associação de Engenheiros Agrônomos do Paraná, 1990. p. 104-119. 